\title{
Reactivity patterns of vanadium(IV/V)-oxo complexes with olefins in the presence of peroxides: A computational study. \\ DOI:
}

10.1039/C9DT03048D

\section{Document Version}

Accepted author manuscript

Link to publication record in Manchester Research Explorer

Citation for published version (APA):

Bin Mubarak, M. Q. E., \& De Visser, S. (2019). Reactivity patterns of vanadium(IV/V)-oxo complexes with olefins in the presence of peroxides: A computational study. Dalton Transactions. https://doi.org/10.1039/C9DT03048D

\section{Published in:}

Dalton Transactions

\section{Citing this paper}

Please note that where the full-text provided on Manchester Research Explorer is the Author Accepted Manuscript or Proof version this may differ from the final Published version. If citing, it is advised that you check and use the publisher's definitive version.

\section{General rights}

Copyright and moral rights for the publications made accessible in the Research Explorer are retained by the authors and/or other copyright owners and it is a condition of accessing publications that users recognise and abide by the legal requirements associated with these rights.

\section{Takedown policy}

If you believe that this document breaches copyright please refer to the University of Manchester's Takedown Procedures [http://man.ac.uk/04Y6Bo] or contact uml.scholarlycommunications@manchester.ac.uk providing relevant details, so we can investigate your claim.

\section{OPEN ACCESS}


Received 00th January 20xx, Accepted 00th January 20xx DOI: $10.1039 / x 0 x \times 00000 x$

\title{
Reactivity patterns of vanadium(IV/V)-oxo complexes with olefins in the presence of peroxides: A computational study.
}

\begin{abstract}
M. Qadri E. Mubarak ${ }^{a}$ and Sam P. de Visser ${ }^{* a}$
Vanadium porphyrin complexes are naturally occuring substances found in crude oil and have been shown to have medicinal properties as well. Little is known on their activities with substrates; therefore, we decided to perform a detailed density functional theory study into the properties and reactivities of vanadium(IV)- and vanadium(V)-oxo complexes with a $\mathrm{TPPCl}_{8}$ or 2,3,7,8,12,13,17,18-octachloro-meso-tetraphenylporphyrinato ligand system. In particular, we investigated the reactivity of $\left[\mathrm{V}^{\mathrm{V}}(\mathrm{O})\left(\mathrm{TPPCl}_{8}\right)\right]^{+}$and $\left[\mathrm{V}^{\mathrm{IV}}(\mathrm{O})\left(\mathrm{TPPCl}_{8}\right)\right]$ with cyclohexene in the presence of $\mathrm{H}_{2} \mathrm{O}_{2}$ or $\mathrm{HCO}_{4}{ }^{-}$. The work shows that vanadium(IV)-oxo and vanadium(V)-oxo are sluggish oxidants by themselves and react with olefins slowly. However, in the presence of hydrogen peroxide these metal-oxo species can be transformed into a side-on vanadium-peroxo complex, which reacts with substrates more efficiently. Particularly with anionic axial ligands, the side-on vanadium-peroxo and vanadium-oxo complexes produced epoxides from cyclohexene with small barier heights. In addition to olefin epoxidation, we investigated aliphatic hydroxylation mechanisms of the same oxidants and some oxidants show efficient and viable cyclohexene hydroxylation mechanisms. The work implies that vanadium-oxo and vanadium-peroxo complexes can react with double bonds through epoxidation, and under certain conditions also give hydroxylation, but the overall reactivity is highly dependent on the equatorial ligand, the local environment and the presence of anionic axial ligands.
\end{abstract}

\section{Introduction}

A transition metal with large natural abundance on Earth is vanadium, but despite this there are only few examples of natural systems including enzymes that utilize a vanadium ion, which is surprising. These vanadium-containing enzymes include vanadium-haloperoxidases and the vanadiumcontaining nitrogenase., ${ }^{1,2}$ In general, the vanadiumhaloperoxidases bind $\mathrm{H}_{2} \mathrm{O}_{2}$ on a nonheme vanadium centre and through additional protons and binding of halide convert this to hypohalide products. In addition, vanadium-porphyrin complexes have been characterized in crude oils, although their function and origin remain unknown. ${ }^{3}$ Moreover, the natural product amavidin is a vanadium(IV) containing compound found in fungi that showed catalase and peroxidase type activity. ${ }^{4}$ Furthermore, evidence has emerged of useful pharmaceutical properties of vanadium containing compounds, whereby, for instance, vanadium-porphyrins are used as anti-HIV agents, ${ }^{5}$ and diaminotris(phenolato) vanadium(V) complexes as anticancer drugs. ${ }^{6}$ In biomimetic chemistry, many reports have appeared in the literature that

\footnotetext{
${ }^{a .}$ The Manchester Institute of Biotechnology and Department of Chemical Engineering and Analytical Science, The University of Manchester, 131 Princess Street, Manchester M1 7DN, United Kingdom
}

Electronic Supplementary Information (ESI) available: absolute and relative energies, group spin densities and charges as well as Cartesian coordinates of optimized structures. See DOI: 10.1039/x0xx00000x discuss the coordination environment and reactivity of vanadium complexes. ${ }^{7,8}$ For instance, vanadium(IV) and vanadium $(\mathrm{V})$ complexes have been shown to react with olefins through epoxidation, ${ }^{9,10}$ but also react with aliphatic groups such as cyclohexane by hydroxylation and desaturation reactions. ${ }^{11} \mathrm{~A}$ recent report showed vanadium complexes to react with olefins through substitution of a $\mathrm{C}-\mathrm{H}$ bond with $\mathrm{C}-\mathrm{X}$ $(\mathrm{X}=\mathrm{Cl}, \mathrm{Br}, \mathrm{l}) .^{12}$ Therefore, they are highly versatile as oxidation catalysts. However, it is not clear whether the reactivity is performed by an $\mathrm{V}^{\mathrm{IV}}(\mathrm{O}), \mathrm{V}^{\mathrm{V}}(\mathrm{O})$ or a vanadium-peroxo complex. To gain insight into the properties and reactivity of vanadium complexes we decided to investigate the structure and reactivity of a set of vanadium(IV)-oxo and vanadium(V)-oxo porphyrins in the presence and absence of $\mathrm{H}_{2} \mathrm{O}_{2}$. Thus, vanadium-porphyrins are well studied and have been characterized with UV-Vis spectroscopy, ${ }^{1} \mathrm{H}$ NMR and EPR spectrometry and X-ray diffraction analysis methods. ${ }^{13}$ These complexes were also found to react efficiently with olefins to form the corresponding epoxides, ${ }^{14}$ although it is unclear whether the active species in a vanadium-oxo or vanadiumperoxo moiety. ${ }^{15}$

Over the years a number of density functional theory calculations have been reported on nonheme and heme vanadium-oxo complexes, ${ }^{16,17}$ but little is known on their activity, what the active oxidant is and how the reactivity compares to high-valent iron(IV)-oxo intermediates. 


\section{ARTICLE}

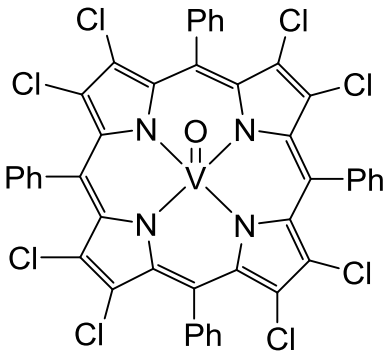

$\left[\mathrm{V}^{\mathrm{V}}(\mathrm{O})\left(\mathrm{TPPCl}_{8}\right)\right]^{+}, \mathrm{B}$ $\left[\mathrm{V}^{\mathrm{IV}}(\mathrm{O})\left(\mathrm{TPPCl}_{8}\right)\right]^{0}, \mathbf{A}$

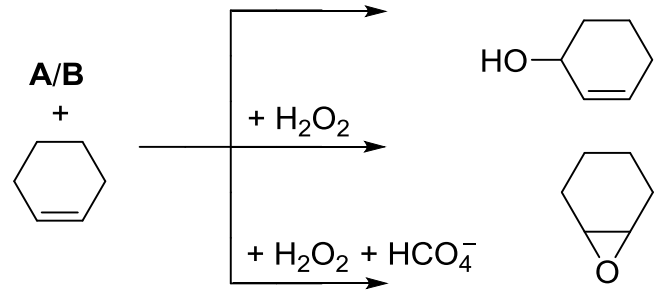

A1/B1:<smiles>C[Al](C)O[CH-]C[C@H]1C=CCCC1</smiles>

A2/B2:

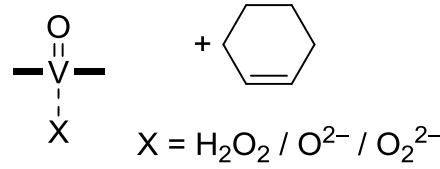

A3/B3:

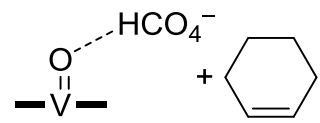

A4/B4:

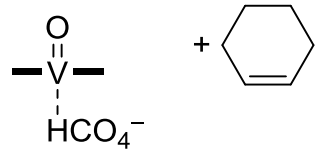

Scheme 1. Model and reaction mechanisms studied in this work.

To find an answer to these questions we set up models of vanadium(IV)-oxo, vanadium(V)-oxo and vanadium-peroxo with porphyrin ligand system and studied substrate activation. Our model follows the system reported in reference 14 and considers a vanadium(IV/V)-oxo ion embedded into a $2,3,7,8,12,13,17,18$-octachloro-meso-tetraphenylporphyrinato group $\left(\mathrm{TPPCl}_{8}\right)$, Scheme 1 . We studied a direct reaction of these complexes with cyclohexene to give either epoxide or enol products. In addition, we considered reaction mechanisms in the presence of $\mathrm{H}_{2} \mathrm{O}_{2}$ and/or peroxymonocarbonate $\left(\mathrm{HCO}_{4}^{-}\right)$. The work shows that vanadium-oxo by itself is a sluggish oxidant, but in a reaction with hydrogen peroxide can be converted into a vanadiumperoxo group, which is considerably more reactive with substrates.

\section{Methods}

Density functional theory (DFT) methods were applied as implemented in the Gaussian-09 software package. ${ }^{18}$ In general, the unrestricted $B 3 L_{Y P}{ }^{19}$ hybrid density functional method was used for geometry optimizations, constraint geometry scans and frequency calculations. All structures were optimized without constraints with an LanL2DZ basis set on vanadium (with core potential) and 6-31G* on the rest of the atoms $(\mathrm{H}, \mathrm{C}, \mathrm{Cl}, \mathrm{N}, \mathrm{O})$ : basis set $\mathrm{BS} 1 .{ }^{20}$ Single point energy calculations were performed to improve the energetics and used a triple- $\zeta$ quality basis set on vanadium (with core potential), i.e. $L A C V 3 P+$, and $6-311+G^{*}$ on the rest of the atoms: basis set BS2. Solvent corrections were included during the geometry optimizations through the continuum polarized conductor model (CPCM) with a dielectric constant mimicking that of toluene. All local minima were characterized with real frequencies only and the transition states had a single imaginary mode for the correct transition. For a selection of structures and potential energy profiles we also did geometry optimizations using a modest 6-31G basis set on all atoms and LanL2DZ with core potential on vanadium: basis set BS3. These results gave almost identical structures and energetics to those obtained with the larger basis set, see Electronic Supporting Information for details. 
(a)

side view:

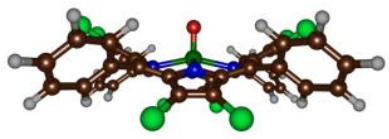

VO: $1.568(1.583) \AA$ $\mathrm{VN}_{\text {average }}: 2.032(2.076) \AA$

$\Delta_{\mathrm{VN}}: 0.512(0.536) \AA$

$v_{\mathrm{VO}}: 1120(1094) \mathrm{cm}^{-1}$

${ }^{1} \mathbf{B}\left({ }^{2} \mathbf{A}\right)$

\section{top view:}

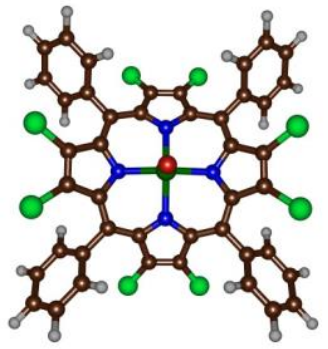

(b)
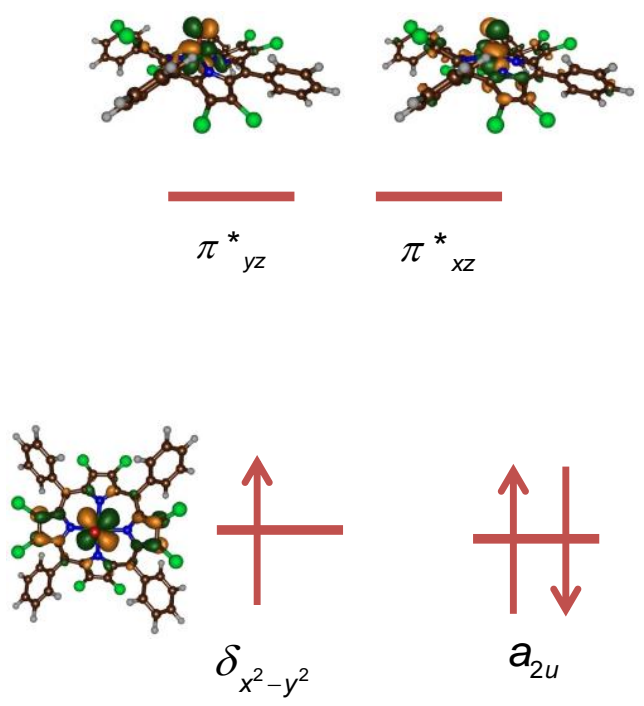

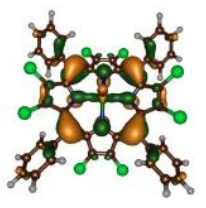

$a_{2 u}$

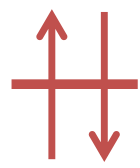

$a_{1 u}$

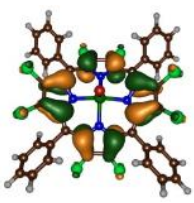

Fig. 1. Optimized geometries of ${ }^{2} \mathbf{A}$ and ${ }^{1} \mathbf{B}$ as obtained at UB3LYP/BS1 in Gaussian-09. Bond lengths are in angstroms and the vibrational frequencies ( wo $_{\mathrm{w}}$ ) in $\mathrm{cm}^{-1}$. The right-handside gives relevant valence orbitals with orbital occupation of ${ }^{2} \mathbf{A}$.

The models contained the full $\left[\mathrm{V}^{\mathrm{V}}(\mathrm{O})\left(\mathrm{TPPCl}_{8}\right)\right]^{+}$(model $\left.\mathbf{B}\right)$ and $\left[\mathrm{V}^{\mathrm{IV}}(\mathrm{O})\left(\mathrm{TPPCl}_{8}\right)\right]^{0}$ (model A) complexes with peripheral substituents on the porphyrin unit included (Scheme 1). Subsequently, we added $\mathrm{H}_{2} \mathrm{O}_{2}$ to our system either on the distal side, i.e. on the vanadium-oxo side (models A1 and B1), but also included a model without distal $\mathrm{H}_{2} \mathrm{O}_{2}$ and a ligand in the axial positions. Thus, models $\mathbf{A} 2$ and $\mathbf{B 2}$ have $\mathrm{H}_{2} \mathrm{O}_{2}$ in the axial position, models A2'/B2' have an axial oxo group and A2"/B2" an axial peroxo moiety.

Cyclohexene was used as a model substrate and was located at the distal side of the vanadium-oxo complex and reaction mechanisms for its epoxidation and aliphatic hydroxylation pathways were studied. In addition to these models we investigated a system with $\mathrm{HCO}_{4}^{-}$as terminal oxidant rather than $\mathrm{H}_{2} \mathrm{O}_{2}$ and repeated the calculated mechanisms: Models A3/B3 with $\mathrm{HCO}_{4}^{-}$on the distal side and models A4/B4 with $\mathrm{HCO}_{4}{ }^{-}$on the axial side. Vibrational frequencies reported here are unscaled values.

\section{Results and discussion}

Before discussing the reactivity patterns of the various vanadium-oxo and vanadium-peroxo complexes, we will start with a detailed analysis of the reactant complexes, namely
$\left[\mathrm{V}^{\mathrm{IV}}(\mathrm{O})\left(\mathrm{TPPCl}_{8}\right)\right]^{0}$ representing

(A) and $\left[\mathrm{V}^{\mathrm{V}}(\mathrm{O})\left(\mathrm{TPPCl}_{8}\right)\right]^{+}$(B) with $\mathrm{TPPCl}_{8}$ 2,3,7,8,12,13,17,18-octachloro-mesotetraphenylporphyrinato. Thus, the vanadium(IV) complex is charge neutral and in a doublet spin ground state, while the vanadium(V) has closed-shell singlet spin state and is singly charged (+1). These spin states match vanadium-oxo porphyrins experimentally characterized with electron paramagnetic resonance (EPR) spectrocopy. ${ }^{13,14}$ Optimized geometries and valence orbitals of the electronic ground states of $\mathbf{A}$ and $\mathbf{B}$ are given in Fig. 1. The optimized geometries of the $\mathrm{V}^{\mathrm{IV}}(\mathrm{O})$ and $\mathrm{V}^{\mathrm{V}}(\mathrm{O})$ porphyrin complexes $\mathrm{A}$ and $\mathbf{B}$ are very similar with $\mathrm{V}-\mathrm{O}$ distances of 1.568 and $1.583 \AA$, respectively. As a consequence the $\mathrm{V}-\mathrm{O}$ stretch vibration is similar too: 1120 (1094) $\mathrm{cm}^{-1}$ for A (B).

Our optimized geometries and vibrational frequencies are in good quantitative agreement with experimentally reported structures and vibrational frequencies of analogous complexes. ${ }^{13 c, 13 d, 14}$ The $\mathrm{V}=\mathrm{O}$ bond lengths are considerably shorter than those calculated for iron(IV)-oxo species but are close to the triple bond found for $\mathrm{Mn}^{\mathrm{V}}$-oxo. ${ }^{21,22}$ This is not surprising as iron(IV)-oxo has four metal 3d-type electrons and two of those form a triplet pair of antibonding interactions for the $\mathrm{FeO} \pi^{*}$ bond that elongate the $\mathrm{Fe}-\mathrm{O}$ distance. As a result of this the vibrational frequency is also well higher than that 
typically found for iron(IV)-oxo complexes, where $\mathrm{Fe}-\mathrm{O}$ frequencies in the order of $800-900 \mathrm{~cm}^{-1}$ were reported. ${ }^{23}$ The origin of the short $\mathrm{V}-\mathrm{O}$ distances in ${ }^{2} \mathbf{A}$ and ${ }^{1} \mathbf{B}$ is related to the orbital occupation (right-hand-side of Fig. 1). Thus, the vanadium(V)-oxo species has valence orbitals that represent the metal-oxo and metal-ligand interactions. Lowest in energy is the $\delta_{x 2-y 2}$ orbital, which is a non-bonding orbital in the plane of the porphyrin ring. Higher in energy and virtual are two $\pi^{*}$ orbitals $\left(\pi^{*}{ }_{x z}\right.$ and $\left.\pi^{*}{ }_{y z}\right)$ for the antibonding interaction of the $3 d_{x z}$ and $3 d_{y z}$ on vanadium with the $2 p_{x}$ and $2 p_{y}$ on oxygen. In iron(IV)-oxo species these two orbitals are singly occupied and due to their antibonding character lead to elongation of the $\mathrm{Fe}-\mathrm{O}$ bond to typically $1.65 \AA$. With vanadium the two $\pi^{*}$ orbitals are virtual and consequently the $\mathrm{V}=\mathrm{O}$ distances are much shorter as there is lesser antibonding character along those bonds. The vanadium-porphyrin system also has two high-lying $\pi$-orbitals on the ligand labelled as $a_{1 \mathrm{u}}$ and $a_{2 \mathrm{u}}$. In cytochrome P450 Compound $\mathrm{I}^{24}$ the $a_{2 \mathrm{u}}$ orbital is singly occupied but in the vanadium systems this orbital is much lower in energy and doubly occupied and hence the valence orbitals are all metal-oxo based. The electronic ground state of ${ }^{2} \mathbf{A}$ and ${ }^{1} \mathbf{B}$, therefore is: $\delta_{\mathrm{x} 2-\mathrm{y} 2}{ }^{1} a_{1 \mathrm{u}}{ }^{2} a_{2 \mathrm{u}}{ }^{2}$ for ${ }^{2} \mathbf{A}$ and $a_{1 \mathrm{u}}{ }^{2} a_{2 \mathrm{u}}{ }^{2}$ for ${ }^{1} \mathbf{B}$ with all metal-type orbitals unoccupied.

The porphyrin is considerably distorted from planarity and is saddle-shaped with the metal 0.512 and $0.536 \AA$ above the plane through the four nitrogen atoms as defined as $\Delta_{\mathrm{VN}}$. This distortion of the planarity was also seen in crystal structures of vanadium-oxo porphyrin complexes, ${ }^{13 c}$ although in ironporphyrin the calculations often converge to a planar structure. Overall, our optimized geometries match previous calculations on ${ }^{2} \mathbf{A}$ perfectly with similar bond distances, porphyrin saddling and the displacement of the metal from the plane through the four nitrogen atoms. ${ }^{14}$

\section{Mechanism of cyclohexene epoxidation by $\mathrm{A} 1 / \mathrm{B} 1+\mathrm{H}_{2} \mathrm{O}_{2}$}

The vanadium(IV)-oxo complex $A$ in the presence of $\mathrm{H}_{2} \mathrm{O}_{2}$ and cyclohexene was found to convert substrate into a mixture of epoxide, cyclohexenol and cyclohexanone products. ${ }^{14}$ To understand these product distributions and the oxidant involved in these transformations, we investigated the mechanism of substrate epoxidation by vanadium(IV)-oxo and vanadium(V)-oxo complexes. We started with a model that includes $\mathrm{H}_{2} \mathrm{O}_{2}$ and cyclohexene as a substrate on the distal site of the vanadium-oxo group: models $\mathbf{A} \mathbf{1}$ and $\mathbf{B 1}$, which we identify with a subscript after the label. Initially a reactant complex (Re) was calculated of the vanadium-oxo group in hydrogen bonding distance to $\mathrm{H}_{2} \mathrm{O}_{2}$ and cyclohexene in its vicinity. The mechanism starts with proton transfer from $\mathrm{H}_{2} \mathrm{O}_{2}$ to the oxo group and simultaneous binding of the hydroperoxo moiety to the vanadium centre to form intermediate Int1 via a transition state TS1. Thereafter, a second proton transfer takes place via transition state TS2 to form a side-on vanadiumperoxo with water ligand Int2, whereby the water is released from the metal centre via transition state TS3 to form the vanadium-peroxo-porphyrin complex Int3. Note that in the mechanism starting with the vanadium(IV)-oxo complex (A1) the water release happens simultaneously with TS2 and no stable Int2 and TS3 structures could be characterized. Finally, the side-on peroxo species (Int3) reacts with olefin via a concerted oxygen atom transfer to form epoxide products (P) via a transition state TS4.

Fig. 2 displays the potential energy landscape of cyclohexene activation by $\mathbf{A} \mathbf{1} / \mathbf{B} 1+\mathrm{H}_{2} \mathrm{O}_{2}$. In the case of the mechanism of $\mathrm{B} 1+\mathrm{H}_{2} \mathrm{O}_{2}$, we calculated the full reaction pathway with UB3LYP/BS1 and UB3LYP/BS3. However, the effect of the basis set on the optimized geometries and bond activation energies for the reaction of model $\mathbf{B} 1$ appears to be very small and most energies are well within $1 \mathrm{kcal} \mathrm{mol}^{-1}$. Hence, we will focus on the BS1 results only here.

The initial proton transfer via TS1 has a barrier of $\triangle \mathrm{E}+\mathrm{ZPE}+\mathrm{E}_{\text {solv }}$ $=16.5$ and $23.8 \mathrm{kcal} \mathrm{mol}^{-1}$ for the pathway starting with the vanadium(V)-oxo (B1) and vanadium(IV)-oxo (A1), respectively. These proton-transfers from $\mathrm{H}_{2} \mathrm{O}_{2}$ to vanadium-oxo species lead to the end-on hydroperoxo-hydroxo-vanadium complexes as a local minimum. Complexes $\mathbf{I n t} \mathbf{1}_{\mathbf{A} \mathbf{1}}$ are considerably less stable than the reactant vanadium-oxo complexes, while the reaction is thermoneutral for the vanadium(V)-oxo species. Moreover, the porphyrin is displaced from planarity upon proton transfer: in $\mathbf{I n t} \mathbf{1}_{\mathbf{A} \mathbf{1}}$ the metal is above the porphyrin plane by $0.825 \AA$. However, no major shift in spin density distributions (Table S13, Electronic Supporting Information) is seen during this proton transfer step. Therefore, TS1 is a pure proton transfer and the activation of $\mathrm{V}(\mathrm{IV})$ or $\mathrm{V}(\mathrm{V})$ complexes requires the same amount of energy. This is not surprising as no electron transfer takes place here and the oxidation state of the metal stays the same. The barriers; however, for proton transfer are rather high in energy and the reaction will be very slow even at room temperature. The proton transfer transition states (Fig. 2) have a large imaginary frequency typical for fast moving protons. ${ }^{25}$ Moreover, the proton transfer happens at short O-H distances.

In the next stage of the mechanism, the hydroperoxo loses a proton to the hydroxo group to form water and binds as a side-on vanadium-peroxo in Int2 in a highly exothermic reaction step followed by a small barrier (TS3) for water release. Indeed the imaginary frequency for this step is considerably lower than that for TS1. The structures are early on the potential energy landscape, i.e. with long $\mathrm{O}-\mathrm{H}$ and short OO-H distances. 


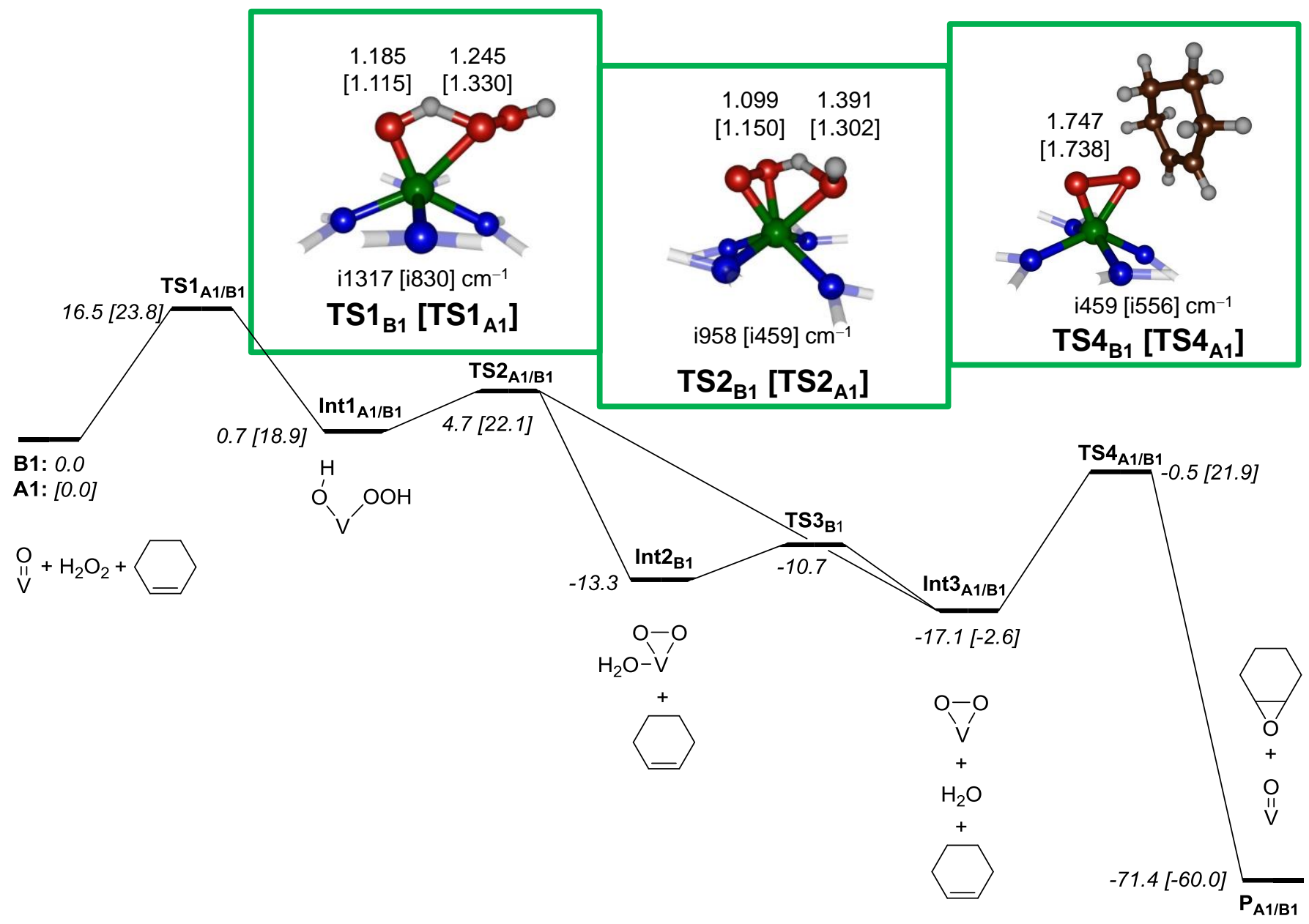

Fig. 2. Potential energy ( $\triangle E+Z P E)$ landscape with energies in kcal mol ${ }^{-1}$ for the reaction of ${ }^{2} \mathbf{A} 1$ and ${ }^{1} \mathbf{B} 1$ with $\mathrm{H}_{2} \mathrm{O}_{2}$ and cyclohexene (CH) as obtained with DFT methods in Gaussian09. Geometry optimizations done at UB3LYP/BS1. Extracts of the transition state structures are given with bond lengths are in angstroms and the imaginary frequencies in $\mathrm{cm}^{-1}$. Data for model $\mathbf{A} \mathbf{1}$ is in square brackets.

The final part of the mechanism involves the attack of the sideon vanadium-peroxo onto the substrate to form epoxide in a concerted reaction step, whereby one oxygen atom of the peroxo group approaches the middle of the double bond with approximately equal distance to each of the carbon atoms of that bond. Barriers of 16.6 and $24.5 \mathrm{kcal} \mathrm{mol}^{-1}$ are obtained for the epoxidation barriers from $\ln \mathbf{t} \mathbf{3}_{\mathrm{A} \mathbf{1}}$ and $\ln \mathbf{t} \mathbf{3}_{\mathrm{B} \mathbf{1}}$, respectively. Typical reaction mechanisms observed for substrate epoxidation by metal-oxo oxidants usually give a stepwise reaction pathway via a radical intermediate with an initial $\mathrm{C}-\mathrm{O}$ bond formation and followed by a ring-closure step. ${ }^{26}$ Here, however, the radical intermediates appear less stable and product is formed in a single concerted epoxidation step. The imaginary frequency represents simultaneous $\mathrm{O}-\mathrm{O}$ bond cleavage and $\mathrm{C}-\mathrm{O}$ bond formation as expected for this transition state.

Overall, the two side-on peroxo complexes Int3 $\mathbf{B}_{\mathrm{A} 1}$ and $\operatorname{Int} \mathbf{3}_{\mathrm{B} 1}$ are seen to react with cyclohexene with barriers that would be accessible at room temperature conditions; particularly the pathway from Int3 $\mathbf{A}_{\mathbf{A} 1}$. As such the side-on peroxo complex A1 should be a viable oxidant of oxygen atom transfer reactions. However, the barriers for the conversion of the vanadium-oxo complexes into the vanadium-peroxo through the use of $\mathrm{H}_{2} \mathrm{O}_{2}$ are of similar magnitude as the substrate activation barriers. Therefore the reaction is not expected to proceed through a clean first-order (or pseudo-first order) reaction mechanism and hence measuring rate constants may be misleading. Indeed, experimental work showed that $\mathrm{HCO}_{4}{ }^{-}$was needed as promotor to trigger a fast reaction process. ${ }^{14}$ Consequently, we investigated some alternative pathways and structures to generate a vanadium-peroxo active species particularly in the presence of promotors or through the binding of axial ligands to the vanadium centre. In addition, we also explored reaction pathways with cyclohexene to form alcohol products.

\section{Mechanism of cyclohexene hydroxylation by $\mathrm{A1} / \mathrm{B} 1+\mathrm{H}_{2} \mathrm{O}_{2}$}

Next, we investigated cyclohexene hydroxylation by models A1/B1. Of course, the mechanism proceeds like that shown in Fig. 2 above with two proton transfer steps (via TS1 and TS2) and the formation of a side-on vanadium-peroxo complex and a water molecule (Int2). 

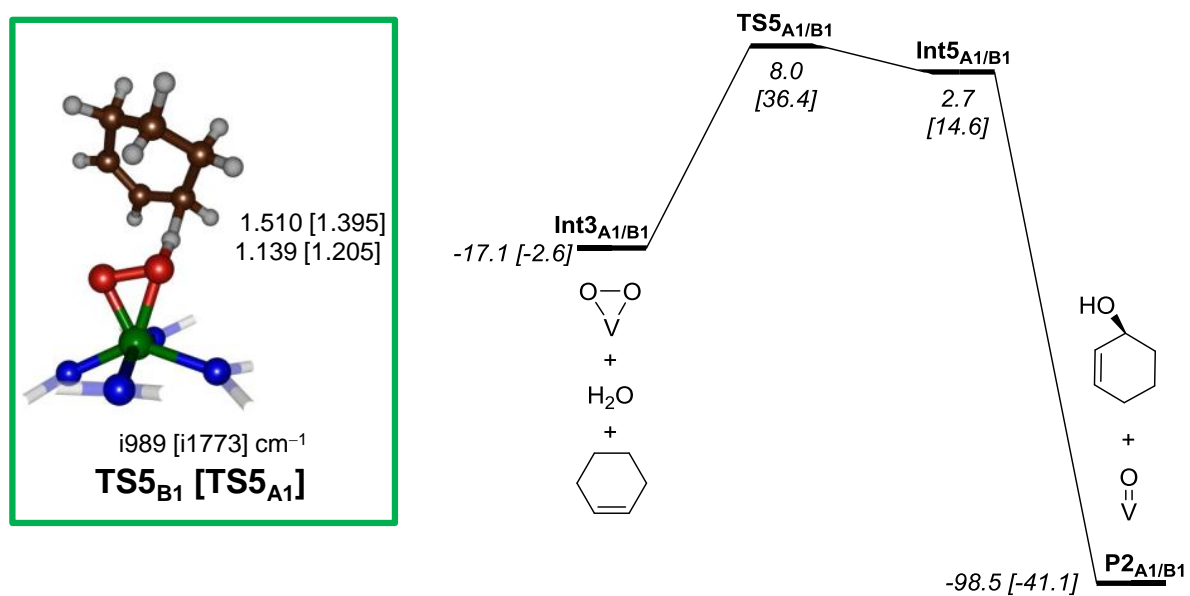

Fig. 3. Potential energy landscape with energies in kcal mol ${ }^{-1}$ for the hydroxylation reaction of cyclohexene by ${ }^{2} \mathbf{A} 1$ and ${ }^{1} \mathbf{B} 1$ in the presence of $\mathrm{H}_{2} \mathrm{O}_{2}$ as obtained with $\mathrm{DFT}$ methods in Gaussian-09. Mechanism started from the vanadium-peroxo intermediate. Geometry optimizations done at UB3LYP/BS1. Bond lengths are in angstroms and the imaginary frequencies in $\mathrm{cm}^{-1}$.

Again release of the water molecule from the vanadium centre gives intermediate Int3. From this point onwards; however, the cyclohexene epoxidation and hydroxylation mechanisms diverge. Thus, the peroxo group abstracts a hydrogen atom from substrate (via a transition state TS5) to form a vanadiumhydroperoxo complex (Int5), while an $\mathrm{OH}$ rebound barrier (TS6) then leads to the 1-hydroxocylohexene products (P2). The obtained potential energy profile of this process is given in Fig. 3. The transition states $\mathbf{T S} \mathbf{5}_{\mathbf{A} \mathbf{1}}$ and $\mathbf{T S} \mathbf{5}_{\mathbf{B} \mathbf{1}}$ are relatively high in energy and values of 39.0 and $25.1 \mathrm{kcal} \mathrm{mol}^{-1}$ are obtained for the pathways starting from the $\mathrm{V}^{\mathrm{IV}}(\mathrm{O})$ and $\mathrm{V}^{\mathrm{V}}(\mathrm{O})$ complexes, respectively. An analysis of the group spin densities gives no radical character of the substrate for the $V(V)$ process, while a spin of 1 is found in the V(IV) pathway. Therefore, the vanadium(V)-oxo will react via proton abstraction of substrate, while a hydrogen atom abstraction is found by the vanadium(IV)-oxo complex. Nevertheless, a barrier with a magnitude of $25.1 \mathrm{kcal} \mathrm{mol}^{-1}$ implicates a sluggish hydrogen atom abstraction process, whereas one of $39.0 \mathrm{kcal} \mathrm{mol}^{-1}$ is too high to be overcome under room temperature and atmospheric pressure conditions. Consequently, the high reaction barriers found for the side-on peroxo complexes imply that these species will be not be able to react by aliphatic hydroxylation pathways, but can react through oxygen atom transfer to olefins.

Optimized geometries of the hydrogen atom abstraction transition states are shown in Fig. 3. The hydrogen atom abstraction transition state for the vanadium(V)-oxo reaction is late with a long $\mathrm{C}-\mathrm{H}$ distance of $1.510 \AA$ and a relatively short $\mathrm{O}-\mathrm{H}$ distance of $1.139 \AA \AA$. These types of product-type hydrogen atom abstraction barriers often correlate with high energy transition states. ${ }^{27}$ On the other hand, a more central transition state is seen for the vanadium(IV)-oxo pathway, although the energy is very high in energy. After the hydrogen atom/proton abstraction, both complexes relax to an intermediate prior to rebound to form the alcohol product complexes. The intermediates are short-lived and collapse to products with negligible rebound transition state (TS6).

Overall, the calculations show that vanadium-peroxo complexes will not react with aliphatic groups through substrate hydroxylation processes as high energy hydrogen atom abstraction or proton abstraction barriers are found. This matches experimental studies on these systems excellently that obtained $>99 \%$ selectivity towards epoxide product formation. ${ }^{14}$ Thus, the calculations give favourable cyclohexene epoxidation over hydroxylation by a large margin and the chemoselectivity does not appear to be affected by the oxidation state of the vanadium centre in the reactant complex. In previous studies on iron(IV)-oxo reactivity with either propene or cyclohexadiene we investigated competitive epoxidation and hydrogen atom abstraction pathways. ${ }^{28}$ In these studies the two reaction channels were close in energy and small environmental perturbations affected the selectivity and product distributions. Clearly, here the energy gaps are wider apart. To understand the nature of the selectivity patterns, we calculated a number of alternative complexes with either $\mathrm{H}_{2} \mathrm{O}_{2}$, oxo or peroxo bound in the axial position.

\section{Mechanism of cyclohexene epoxidation by $\mathrm{A} 2 / \mathrm{B} 2+\mathrm{H}_{2} \mathrm{O}_{2}$}

Therefafter, we investigated cyclohexene epoxidation from models A2/B2, which have the $\mathrm{H}_{2} \mathrm{O}_{2}$ molecule trans to the vanadium-oxo group and hence the oxygen atom transfer is from the oxo group rather than from $\mathrm{H}_{2} \mathrm{O}_{2}$. The optimized $\mathrm{C}-\mathrm{O}$ bond activation transition states TS4 $_{\mathrm{A} 2}$ and $\mathbf{T S} \mathbf{4}_{\mathrm{B} 2}$ are shown in Fig. 4. By contrast to the concerted epoxidation transition states shown in Fig. 2 for models $\mathbf{A 1}$ and $\mathbf{B 1}$, the $\mathbf{T S 4}_{\mathrm{A} 2}$ and TS4 $_{B 2}$ structures are geometrically very different. Thus, in TS4 $_{A 1}$ and TS4 $_{B 1}$ the peroxo group attacks the midpoint of the $\mathrm{C}=\mathrm{C}$ bond of the olefin and both $\mathrm{C}-\mathrm{O}$ bond of the epoxide are simultaneously formed. By contrast, in TS4 ${ }_{\mathrm{A} 2}$ and TS4 $\mathbf{B}_{\mathrm{B} 2}$ the oxo group attacks on specific carbon atom and single $\mathrm{C}-\mathrm{O}$. 


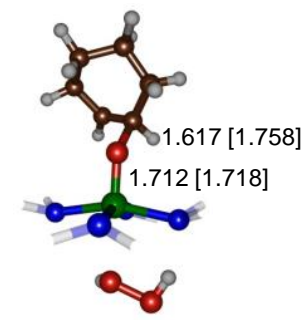

1537 [i702] $\mathrm{cm}^{-1}$

$\Delta \mathrm{E}+\mathrm{ZPE}=50.3[38.2]$

\section{$\mathrm{TS}_{\mathrm{B} 2}\left[\mathrm{TS}_{\mathrm{A} 2}\right]$}

Fig. 4. Optimized $\mathrm{C}-\mathrm{O}$ bond formation transition states (TS5) for models $\mathbf{A} \mathbf{2}$ and $\mathbf{B 2}$. Bond lengths are in angstroms, the imaginary frequency in $\mathrm{cm}^{-1}$ and relative energies in $\mathrm{kcal} \mathrm{mol}^{-1}$.

As such these transition states resemble those seen for stepwise epoxidation reactions, ${ }^{26,29}$ where one $\mathrm{C}-\mathrm{O}$ bond at a time is formed. Usually these stepwise processes proceed through the formation of a radical intermediate. However, here no stable radical intermediates are found and the optimizations collapsed to epoxide products directly. Therefore, the radical intermediates for systems A2 and B2 are shoulders on the potential energy landscape en route to product formation. In previous work this type of pseudoconcerted reaction mechanisms were rationalized as resulting from a strong displacement of the metal from the porphyrin plane that enabled efficient oxygen atom transfer to substrates and hence affected the ring-closure barriers. ${ }^{30}$ For that reason, we decided to also explore alternative vanadiumoxo and vanadium-peroxo complexes with an electrondonating group in the axial position (see next section). Nevertheless, the barriers for oxygen atom transfer from vanadium(V)-oxo and vanadium(IV)-oxo are very high in energy, namely $\triangle E+Z P E+E_{\text {solv }}=50.3$ and $38.2 \mathrm{kcal} \mathrm{mol}^{-1}$, respectively. Therefore, direct oxygen atom transfer by $\left[\mathrm{V}^{\mathrm{V}}(\mathrm{O})\left(\mathrm{TPPCl}_{8}\right)\right]^{+}$or $\left[\mathrm{V}^{\mathrm{IV}}(\mathrm{O})\left(\mathrm{TPPCl}_{8}\right)\right]$ will be unlikely to happen at room temperature and these systems can be considered as sluggish oxidants for oxygen atom transfer reactions.

\section{Mechanism of cyclohexene epoxidation and hydroxylation by A2/B2 without $\mathrm{H}_{2} \mathrm{O}_{2}$}

To test the effect of binding of axial ligands to the vanadiumporphyrin on the reaction mechanism for activation of $\mathrm{H}_{2} \mathrm{O}_{2}$ and substrate, we created models for a vanadium(IV/V)-dioxo complex without $\mathrm{H}_{2} \mathrm{O}_{2}$, namely models $\mathbf{A 2}$ '/ $\mathbf{B 2}$ ' and models of vanadium(IV/V)-peroxo(oxo) without $\mathrm{H}_{2} \mathrm{O}_{2}$ : A2"/B2". Note that all of these models have an oxo group in the trans (axial) position and substrate approaches on the distal site. The mechanism of models of vanadium(IV/V)-peroxo(oxo) namely as A2"/B2" was suggested by the Sankar and Maurya group where they were able to trap and characterize the structures using MALDI-TOF. ${ }^{14 a}$ Furthermore, substitutions on the ligand framework of the porphyrin group were made and the effects on catalysis and turnover studied. ${ }^{14 \mathrm{~b}}$
Fig. 5 displays the potential energy landscape of cyclohexene activation by A2', A2", B2' and B2". In addition, we explored the vanadium-oxo and vanadium-peroxo complexes with different substituents to the porphyrin group. Thus, apart from the $\mathrm{TPPCl}_{8}$ equatorial ligand, we investigated a porphyrin model with only hydrogen atoms as substituents on the mesoposition (R) and $\beta$-position (X), designated ligands A2-H/B2-H. Furthermore, a porphyrin ligand with 3,5-dimethoxyphenyl on the meso-position and hydrogens on the $\beta$-positions was tested: ligands A2-A/B2-A. Finally, a porphyrin ligand with 2,4dibromo-3,5-dimethoxyphenyl on the meso-position and bromide on the $\beta$-positions was studied: ligands A2-B/B2-B. Subsequently, the effect of the equatorial ligand on the reactivity was studied for the vanadium-oxo-peroxo and vanadium-dioxo complexes. Apart from the side-on peroxo, we also calculated an end-on conformation, but find it $\triangle \mathrm{E}+\mathrm{ZPE}=$ 9.1 and $13.0 \mathrm{kcal} \mathrm{mol}^{-1}$ higher in energy as compared to the side-on configuration of $\mathrm{Re}_{\mathrm{A} 2}$ " and $\mathrm{Re}_{\mathrm{A} 2-\mathrm{B}}$ " respectively (See Electronic Supporting Information).. We explored the direct cyclohexene epoxidation and hydroxylation by the vanadium(IV)-oxo, vanadium(V)-oxo complexes, vanadium(IV)peroxo and vanadium(V)-peroxo complexes.

The potential energy landscape and optimized geometries of the electrophilic addition transition states for cyclohexene epoxidation are given in Fig. 5. The optimized geometries shown in Fig. 5 for the vanadium-dioxo and vanadium-oxoperoxo complexes with $\mathrm{TPPCl}_{8}$ ligand represent concerted epoxidation transition states for direct insertion of an oxygen atom into the $\mathrm{C}=\mathrm{C}$ bond of the olefin. Indeed in most structures, the geometry is symmetric and almost equal $\mathrm{C}-\mathrm{O}$ distances are observed. Structurally, therefore they look similar to those reported above with either $\mathrm{H}_{2} \mathrm{O}_{2}$ or water present.

Energetically, the barrier heights of the structures of the vanadium-dioxo in a reaction with cyclohexene are very low in energy; particularly those passing $\mathbf{T S}_{\mathrm{Az}^{\prime}}, \mathbf{T S} \mathbf{4}_{\mathbf{B 2}^{\prime}}$ and $\mathbf{T S} \mathbf{4}_{\mathrm{A2}}$ " where barriers of less than $1 \mathrm{kcal} \mathrm{mol}^{-1}$ are observed. Therefore, these reactions will be extremely fast and efficient and can be a good alternative for the oxidation of olefins to epoxides. The axial ligand is seen to pull the other oxygen atom more into the plane of the porphyrin, which should result in better orbital overlap and a more stable structure. As such the calculations predict that vanadium-dioxo porphyrin is a very efficient oxidant that reacts with substrates rapidly. These vanadium-dioxo models are seen to activate a $\mathrm{C}=\mathrm{C}$ double bond efficiently and react in a concerted pathway to epoxide products. The alternative cyclohexene hydroxylation was also tested. Although the initial hydrogen atom abstraction step is low in energy (barriers less than $5 \mathrm{kcal} \mathrm{mol}^{-}$ ${ }^{1}$ ) actually the $\mathrm{OH}$ rebound step to form products is $11.4 \mathrm{kcal}$ $\mathrm{mol}^{-1}$ for B2' and $6.6 \mathrm{kcal} \mathrm{mol}^{-1}$ for $\mathbf{A 2}^{\prime}$. Nevertheless, with barriers of less than $5 \mathrm{kcal} \mathrm{mol}^{-1}$ for the initial reaction step of epoxidation and hydroxylation, it is likely that these reactions happen in parallel and a mixture of products will be obtained. This result is in good agreement with experimental studies on cyclohexene activation by vanadium-porphyrins that give hydroxylation and epoxidation products. 


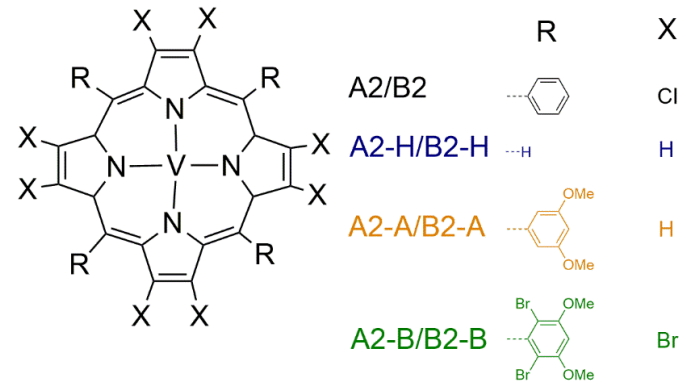

TS4 ${ }_{\text {A2-H"/B2-H" }}:<1.0[<1.0]$ TS4 ${ }_{\text {A2-H'/B2-H' }}: 9.6[<1.0]$

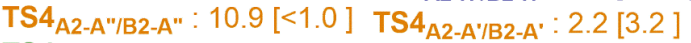

TS4 ${ }_{A 2-B^{\prime} / B 2-B^{\prime \prime}}: 22.0$ [29.1] TS4 $_{\text {A2-B'/B2-B' }} 22.7$ [19.0]

$\mathrm{A}_{2-\mathrm{B} "}\left[\mathrm{~B}_{2-\mathrm{B}} \mathrm{B}\right]: 0.0[0.0]$
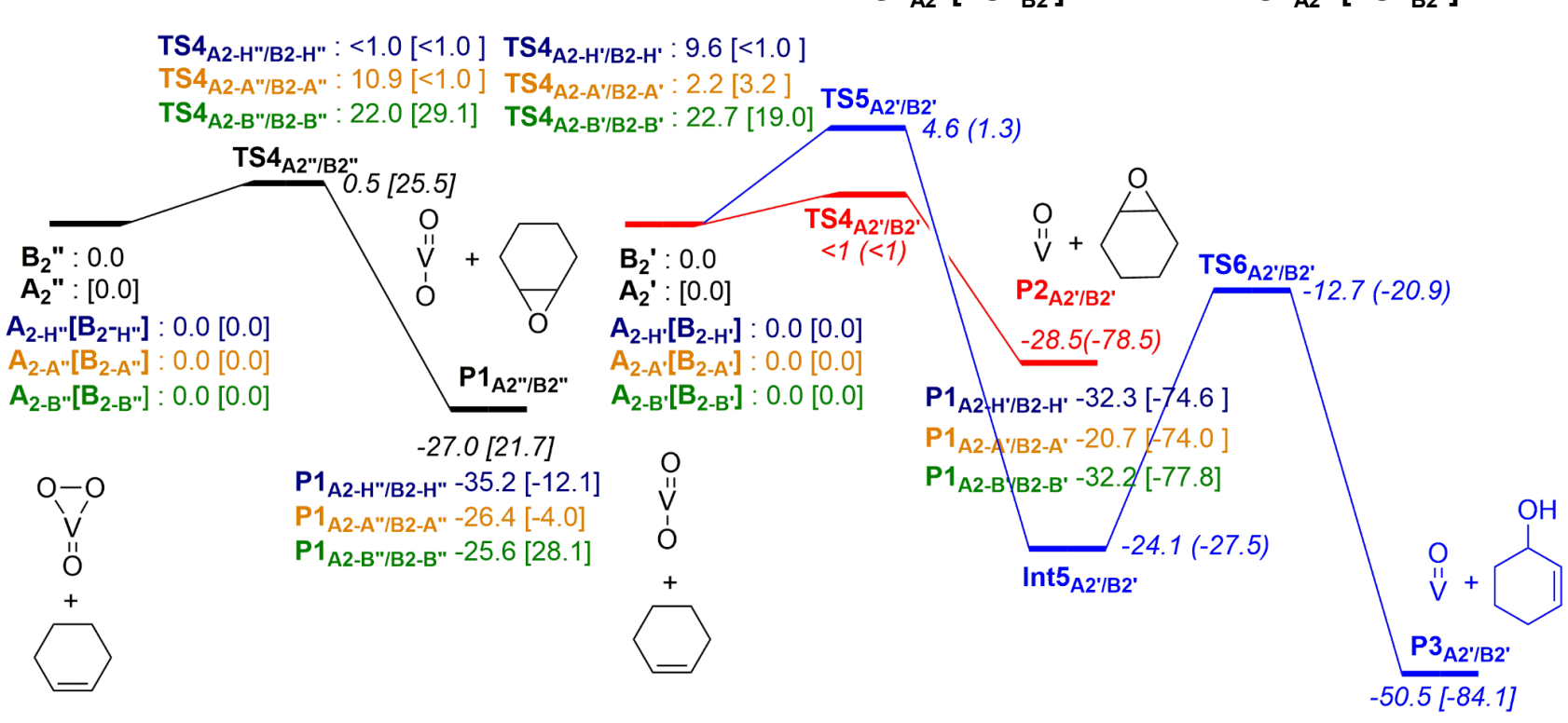

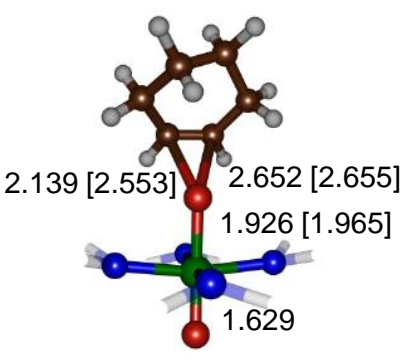

i287 [i134] $\mathrm{cm}^{-1}$

$\mathrm{TS4}_{\mathrm{A} 2},\left[\mathrm{TS4}_{\mathrm{B} 2},\right]$

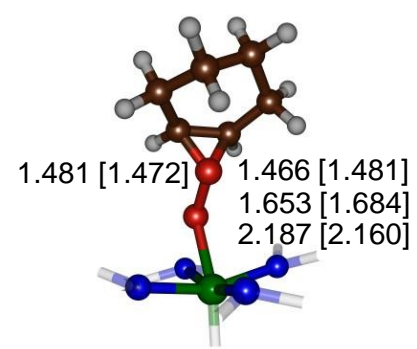

i333 [i356] $\mathrm{cm}^{-1}$ $\mathrm{TS4}_{\mathrm{A2}}, \mathrm{TS}_{\mathrm{B} 2 \text { ", }}$

Fig. 5. Potential energy landscape ( $\triangle \mathrm{E}+\mathrm{ZPE}$ data) with energies in kcal $\mathrm{mol}^{-1}$ for the direct cyclohexene epoxidation and hydroxylation by the vanadium(IV)-oxo, vanadium(V)-oxo complexes, vanadium(IV)-peroxo and vanadium(V)-peroxo complexes with axial oxo group as obtained with DFT methods in Gaussian-09. Geometry optimizations done at UB3LYP/BS1 and energies use basis set BS2. Bond lengths are in angstroms and the imaginary frequencies in $\mathrm{cm}^{-1}$.

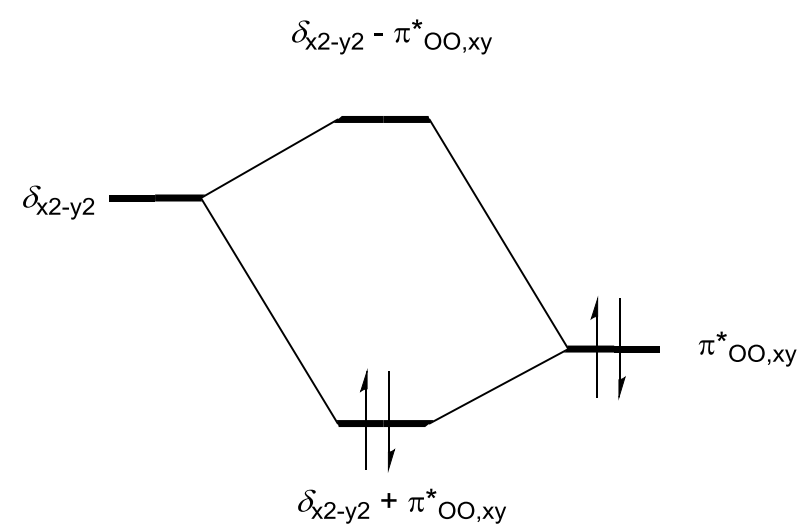

$\delta_{\mathrm{x} 2-\mathrm{y} 2}+\pi^{*} \mathrm{OO}, \mathrm{xy}$

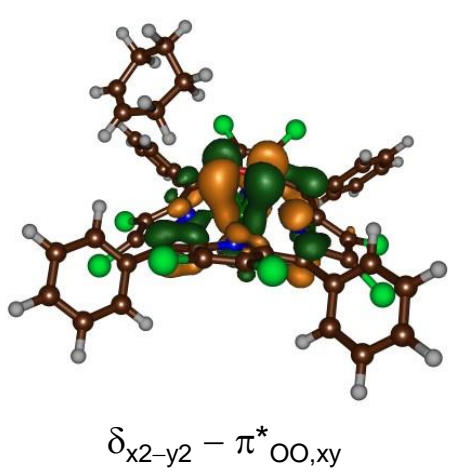

Int3 ${ }_{B 2}$ "

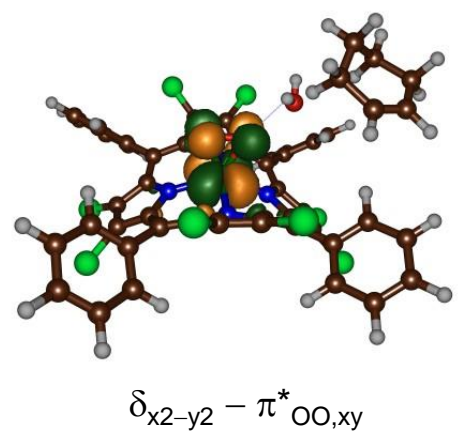

Int3 $3_{B 1}$

Fig. 6. Molecular orbital splitting in vanadium-peroxo complexes for the interaction of the $\pi^{*}{ }_{\mathrm{oo}, \mathrm{xy}}$ orbital on the peroxo group with the $\delta_{\mathrm{xz}-\mathrm{y} 2}$ vanadium-orbital. 
To gain further insight into the chemical system, we replaced the substituents on the periphery of the porphyrin with alternative groups. As follows, seemingly small changes to the ligand system appear to have dramatic effects on the structure and reactivity of vanadium-oxo and vanadium-peroxo complexes. Thus, replacing all substituents with hydrogen atoms results in structures that have almost planar porphyrin rings, similar to previous cytochrome P450 model calculations. ${ }^{31}$ Moreover, with 3,5-dimethoxyphenyl as mesosubstituents most barriers go up in energy significantly due to stereochemical interactions of the approaching substrate to the oxidant and the ideal angles and structures cannot be reached. In particular, the addition of 2,5-dibromo to the meso-phenyl groups reduces the reactivity dramatically with rate determining barriers well over $19 \mathrm{kcal} \mathrm{mol}^{-1}$. As such, vanadium-oxo and vanadium-peroxo complexes appear to be more sensitive to ligand substitution of the porphyrin macrocycle, which affect structure and reactivity. By contrast, in iron(IV)-oxo porphyrins and nonheme iron(V)-oxo tetraamidomacrocyclic ligand as the equatorial ligand, the effects were much smaller. ${ }^{23 e, 28 c, 30 a}$

To understand the axial ligand effect on the orbital shapes and energies we compared the structure and electronic configuration of the vanadium-peroxo complexes $\operatorname{Int} \mathbf{3}_{\mathrm{B} 1}$ and Int3 ${ }_{\text {B2" }}$ in Fig. 6. Thus, without an axial ligand bound to the vanadium centre, as in $\operatorname{Int} \mathbf{3}_{\mathrm{B} 1}$, the vanadium-peroxo group is well displaced from the plane through the four nitrogen atoms of the porphyrin by $\Delta=0.595 \AA$, while it is much closer to the plane in the vanadium-oxo-peroxo complex Int3 ${ }_{\mathrm{B2} \text { ": }} \Delta=$ $0.127 \AA ̊$. As a consequence, the peroxo group enjoys better orbital overlap with orbitals on the porphyrin manifold and the V-O distances are shorter: $1.69 \AA$ in Int $3_{\text {B2" }}$ and 1.79 $A$ in Int3 $\mathbf{B}_{\mathbf{B} 1}$. As shown in Fig. 6 , a strong interaction between the $\delta_{x 2-y 2}$ and $\pi^{*}{ }_{\text {oo,xy }}$ orbitals on the vanadium and peroxo groups, will widen the gap between the bonding and antibonding orbitals and stabilize the bonding orbitals in energy. A similar interaction, but then between $a_{2 \mathrm{u}}$ and a lone-pair $\pi$-orbital on the axial ligand was seen in P450 Compound I and predicted to affect its electron affinity and reduction potential. ${ }^{32} \mathrm{~A}$ stronger pusheffect of the axial ligand was shown to enhance to reactivity of Compound I. ${ }^{33}$

The molecular orbitals for the interaction of $\delta_{x 2-y 2}$ and $\pi^{*}{ }_{00, x y}$ for Int $\mathbf{3}_{\mathrm{B} 1}$ and Int $\mathbf{3}_{\mathrm{B} 2 \text { " }}$ are displayed in Fig. 6 . Without a group in the axial position the interaction is just between these two orbitals, but with the metal inside the plane of the porphyrin, as in Int3 $\mathbf{B}_{\mathbf{B 2}}$, further interactions with the $a_{2 \mathrm{u}}$ orbital are seen, which raise this antibonding orbital further in energy and improve the oxidative power of the vanadium-peroxo moiety as seen from the reaction with cyclohexene. Therefore, vanadium-peroxo oxidants are more powerful oxidants when the vanadium-porphyrin complex has an anionic axial ligand that can pull the metal into the frame of the porphyrin and enable better and stronger orbital overlap.

\section{Mechanism of cyclohexene hydroxylation and epoxidation by $\mathrm{A} / \mathrm{B}+\mathrm{HCO}_{4}^{-}$}

Finally, experimental work on the reaction of vanadium-oxo porphyrins in the presence of oxidant showed enhanced performance of substrate activation with $\mathrm{HCO}_{4}{ }^{-}$in the reaction mixture. ${ }^{14}$ Therefore, we explored the potential energy profile of cyclohexene hydroxylation and epoxidation using a model that contains $\left[\mathrm{V}^{\mathrm{IV} / \mathrm{V}}(\mathrm{O})\left(\mathrm{TPPCl}_{8}\right)\right]^{\mathrm{O} /+}+\mathrm{HCO}_{4}^{-}$and substrate: models A3/B3 in Fig. 7.

We tested two configurations of $\mathrm{HCO}_{4}^{-}$for the reactant complexes, namely bound as either $\mathrm{HOOCO}_{2}^{-}$or $\mathrm{OOC}(\mathrm{O}) \mathrm{OH}^{-}$,

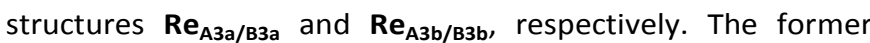
structure with a hydroperoxo group is found to be the most stable conformation by at least $25 \mathrm{kcal} \mathrm{mol}^{-1}$ for both $\mathbf{A}$ and $\mathbf{B}$ systems. The hydroperoxo proton forms an internal hydrogen bond with an oxo group of $\mathrm{HCO}_{4}^{-}$, whereas the hydroxo group in the alternative conformation formed a hydrogen bond with the vanadium-oxo group, see Electronic Supporting Information. Nevertheless, the reactant complexes of $\left[\mathrm{V}^{\mathrm{IV} / \mathrm{V}}(\mathrm{O})\left(\mathrm{TPPCl}_{8}\right]^{\mathrm{O}+}\right.$ with $\mathrm{HCO}_{4}^{-}$, a water molecule and cyclohexene have the $\mathrm{HCO}_{4}^{-}$group bound to the vanadium centre.

We then tested direct oxygen atom activation of cyclohexene to form cyclohexene oxide using these models. The reaction starts from the reactant complexes $\mathbf{R e}_{\mathbf{A} \mathbf{a} \text { /вза, which }}$ are the $\left[V^{\mathrm{IV} / \mathrm{V}}(\mathrm{O})\left(\mathrm{TPPCl}_{8}\right)\right]^{\mathrm{O} /+}$ in complex with $\mathrm{HOOCO}_{2}^{-}, \mathrm{H}_{2} \mathrm{O}$ and cyclohexene. In the first stage of the reaction the $\mathrm{HOOCO}_{2}$ species undergoes an internal proton transfer to form the $\mathrm{OOC}(\mathrm{O}) \mathrm{OH}^{-}$species $\left(\mathbf{R e}_{\text {A3b/B3b }}\right)$. We were not able to locate these transition states; therefore expect them to be close in energy to the $\mathbf{R e}_{\mathbf{A} \mathbf{3 b} / \mathbf{B} 3 \mathbf{b}}$ structures.

In the next step of the reaction, the superoxo group of $\mathrm{OOC}(\mathrm{O}) \mathrm{OH}^{-}$then attacks the olefin bond via an epoxidation transition state $\mathbf{T S} \mathbf{4}_{\mathbf{A} 3 / \mathbf{B} 3}$ to form epoxide products $\left(\mathbf{P} \mathbf{3}_{\mathbf{A} 3 / \mathbf{B} 3}\right)$ in a concerted reaction step. We did not manage to locate transition states for direct activation of the olefin double bond

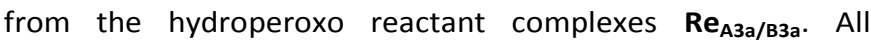
attempts for $\mathrm{C}-\mathrm{O}$ bond formation through constraint geometry scans led to high-energy pathways without the formation of a local minimum. 


\section{ARTICLE}

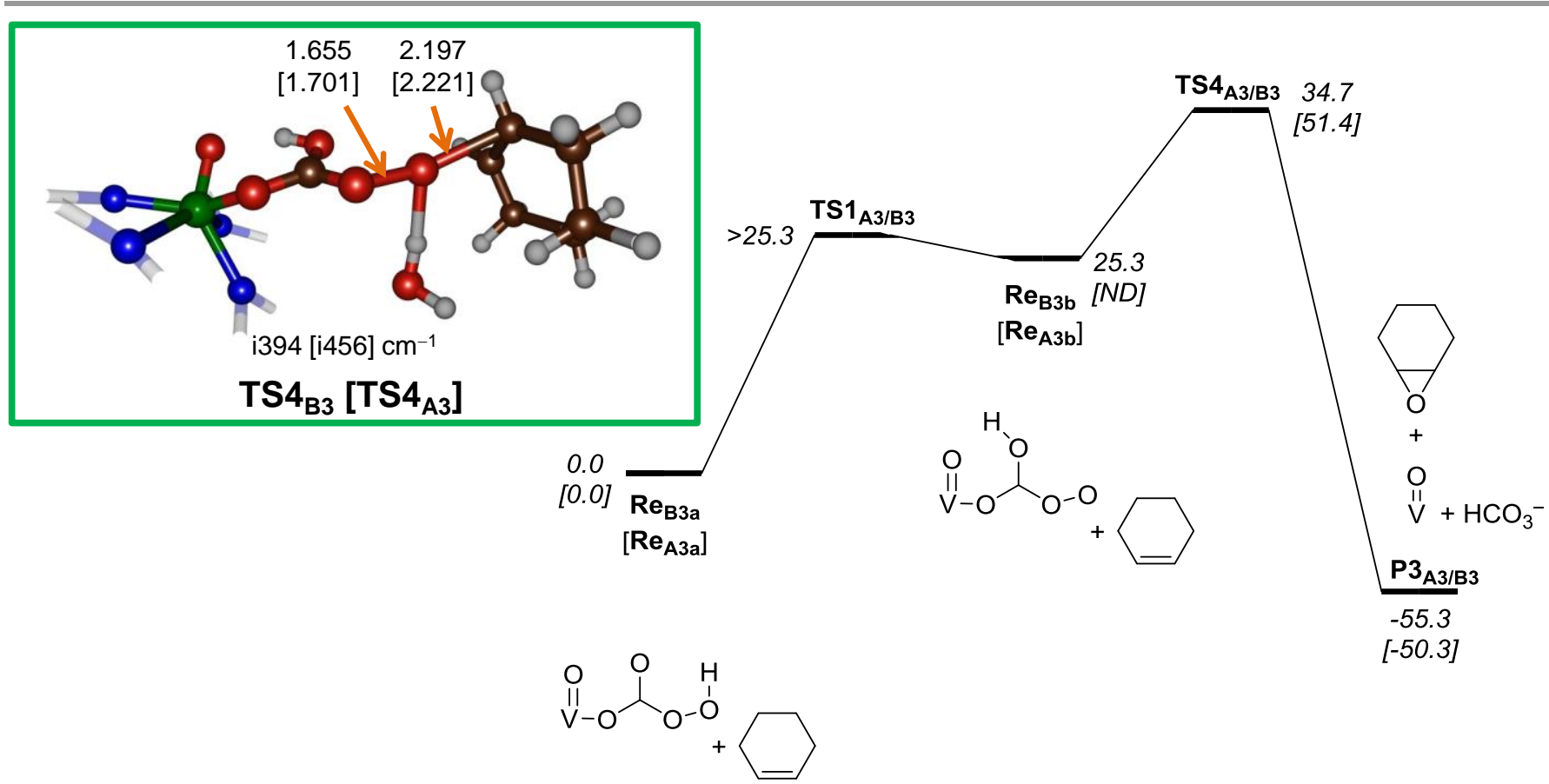

Fig. 7. Potential energy landscape with energies in $\mathrm{kcal} \mathrm{mol}^{-1}$ for the epoxidation reaction of cyclohexene by ${ }^{2} \mathbf{A} 3$ and ${ }^{1} \mathbf{B} 3$ in the presence of $\mathrm{HCO}_{4}{ }^{-}$as obtained with $\mathrm{DFT}$ methods in Gaussian-09. Mechanism started from the vanadium-peroxo intermediate. Geometry optimizations done at UB3LYP/BS1. Bond lengths are in angstroms and the imaginary frequencies in $\mathrm{cm}^{-1}$.

The barriers for substrate activation of complexes $\mathbf{R e}_{\mathbf{A з b} / \mathbf{B} \mathbf{b}}$ are high in energy and are $34.7 \mathrm{kcal} \mathrm{mol}^{-1}$ for the pathway starting from the vanadium(V) complex and $51.4 \mathrm{kcal} \mathrm{mol}^{-1}$ for the one originating from the vanadium(IV) species. Optimized geometries of these transition states are shown in the inset in Fig. 7. The imaginary frequency for the transition state shows attack of the peroxo group on one of the carbon atoms of the olefin only. However, no radical intermediate is formed, but en route to product the ring-closure step takes place. As such the pathway from models $\mathbf{A} \mathbf{3} / \mathbf{B} \mathbf{3}$ has a much less symmetric transition state than that seen for the reaction with $\mathrm{H}_{2} \mathrm{O}_{2}$ as discussed above. The $\mathrm{C}-\mathrm{O}$ bond in the transition state is very long, i.e. $2.197 \AA$ for TS4 $_{B 3}$ and $2.221 \AA$ for TS4 $_{A 3}$. These distances are well longer than the distances of $1.747 / 1.738 \AA$ for the transition states in Fig. 2. Overall the calculations on models A3 and $\mathbf{B} 3$ show that $\mathrm{HCO}_{4}{ }^{-}$is not the active oxidant in the reaction mechanism and is unlikely to be the oxygen transfer agent that generates cyclohexene epoxide products.

\section{Conclusions}

Density functional theory calculations on cyclohexene epoxidation and hydroxylation by vanadium porphyrin complexes are reported. We have conducted a detailed study of vanadium(IV) and vanadium(V) complexes with various models with oxo, peroxo or hydroperoxo groups as well as in the presence of either $\mathrm{H}_{2} \mathrm{O}_{2}$ or $\mathrm{HCO}_{4}^{-}$. In addition, the axial and equatorial ligand effect on the reaction mechanism and reaction rates was investigated. Among all the models explored, we identify several vanadium complexes that are efficient oxidants of oxygen atom transfer reactions to olefins and particularly the vanadium-peroxo and vanadium-oxo complexes with an anionic axial ligand. These axial ligands pull the metal into the plane of the nitrogen porphyrin atoms and enable better orbital overlap; thereby affecting the electron affinity of these complexes and enhancing reaction rates. However, the reactivity, in contrast to iron-porphyrins, is highly sensitive to the equatorial ligand, whereby substituents to the meso-phenyl group - particularly methoxy groups appear to reduce the catalytic performance dramatically. These changes are mostly the result of stereochemical interactions of the approaching substrate to the oxidant. The mechanisms of olefin epoxidation are concerted through a direct oxygen atom transfer rather than a stepwise reaction via a radical intermediate. This implies that we do not expect side reactions through isomerization and cis/trans scrambling of 
products. Overall, the work shows that olefin epoxidation by vanadium-oxo and vanadium-peroxo complexes should be highly efficient under the right conditions where a good oxidant is generated and this is in agreement with experimental work done previously. Moreover, these oxidants are expected to be highly specific and should produce limited amount of by-products in contrast to analogous ironporphyrins.

\section{Conflicts of interest}

There are no conflicts to declare.

\section{Acknowledgements}

M.Q.E.M. thanks the Ministry of Higher Education Malaysia and USIM for a studentship.

\section{Notes and references}

1 a) A. Butler, Coord. Chem. Rev., 1999, 187, 17; b) J. Littlechild, E. Garcia-Rodriguez, A. Dalby and M. Isupov, J. Mol. Recognit., 2002, 15, 291; c) J. M. Winter and B. S. Moore, J. Biol. Chem., 2009, 284, 18577; d) R. Wever and M. A. van der Horst, Dalton Trans., 2013, 42, 11778; e) C. Leblanc, H. Vilter, J.-B. Fournier, L. Delage, P. Potin, E. Rebuffet, G. Michel, P. L. Solari, M. C. Feiters and M. Czjzek, Coord. Chem. Rev., 2015, 301, 134; f) R. Wever and P. Barnett, Chem. Asian J., 2017, 12, 1997; g) C. C. McLauchlan, H. A. Murakami, C. A. Wallace and D. C. Crans, J. Inorg. Biochem., 2018, 186, 267; h) A. Timmins and S. P. de Visser, Adv. Protein Chem. Struct. Biol., 2015, 100, 113.

2 a) B. K. Burgess and D. J. Lowe, Chem. Rev., 1996, 96, 2983; b) Y. Hu and M. W. Ribbe, Methods Mol. Biol., 2011, 766, 3 c) B. M. Hoffman, D. Lukoyanov, D. R. Dean and L. C Seefeldt, Acc. Chem. Res., 2013, 46, 587; d) R. R. Eady, S. V. Antonyuk and S. S. Hasnain, Curr. Opin. Chem. Biol., 2016, 31, 103.

3 a) X. Zhao, Q. Shi, M. R. Gray and C. Xu, Sci. Rep., 2014, 4 5373; b) K. Qiana, T. R. Fredriksen, A. S. Mennito, Y. Zhang, M. R. Harper, S. Merchant, J. D. Kushnerick, B. M. Rytting and P. K. Kilpatrick, Fuels, 2019, 239, 1258.

4 J. A. L. da Silva, J. J. R. Fraústo da Silva and A. J. L. Pombeiro, Coord. Chem. Rev. 2013, 257, 2388.

5 S.-Y. Wong, R. W.-Y. Sun, N. P.-Y. Chung, C.-L. Lin and C.-M. Che, Chem. Commun., 2005, 3544.

6 a) K. H. Thompson, J. H. McNeill and C. Orvig, Chem. Rev., 1999, 99, 2561; b) L. Reytman, J. Hochman and E. Y. Tshuva, J. Coord. Chem., 2018, 71, 11.

7 a) G. Licini, V. Conte, A. Coletti, M. Mba and C. Zonta, Coord. Chem. Rev., 2011, 255, 2345; b) M. Sutradhara, L. M. D. R. S. Martinsa, M. F. C. Guedes da Silva and A. J. L. Pombeiro, Coord. Chem. Rev., 2015, 301, 200; c) R. R. Langeslay, D. M. Kaphan, C. L. Marshall, P. C. Stair, A. P. Sattelberger and M. Delferro, Chem. Rev., 2019, 119, 2128; d) T. S. Smith II, R. LoBrutto and V. L. Pecoraro, Coord. Chem. Rev., 2002, 228, 1.

8 a) J. P. Fox, B. Ramdhanie, A. A. Zareba, R. S. Czernuszewicz, and D. P. Goldberg, Inorg. Chem., 2004, 43, 6600; b) R. Harada, H. Okawa and T. Kojima, Inorg. Chim. Acta, 2005, 358, 489; c) E. Hoppe, C. Limberg and B. Ziemer, Inorg. Chem., 2006, 45, 8308; d) M. K. Hossain, M. Haukka, G. C. Lisensky, A. Lehtonen and E. Nordlander, Inorg. Chim. Acta, 2019, 487, 112; e) R. K. Egdal, F. B. Larsen, A. D. Bond and C.
J. McKenzie, Inorg. Chim. Acta, 2005, 358, 376; f) G. J. Colpas, B. J Hamstra, J. W. Kampf and V. L. Pecoraro, J. Am. Chem. Soc., 1996, 118, 3469; g) J. Yudenfreund Kravitz and V. L. Pecoraro, Pure Appl. Chem., 2005, 77, 1595.

9 M. Sedighipoor, A. H. Kianfar, W. A. K. Mahmood and M. H. Azarian, Inorg. Chim. Acta, 2017, 457, 116.

10 a) C. Cordelle, D. Agustin, J.-C. Daran and R. Poli, Inorg. Chim. Acta, 2010, 364, 144; b) M. Vandichel, K. Leus, P. Van Der Voort, M. Waroquier and V. Van Speybroeck, J. Catal., 2012, 2012, 294, 1; c) P. Salonen, A. Peuronen and A. Lehtonen, Inorg. Chem. Commun., 2017, 86, 165.

11 a) G. S. Mishra and A. Kumar, Catal. Lett., 2002, 81, 1; b) J. Zhang, H. Yang, T. Sun, Z. Chen and G. Yin, Inorg. Chem., 2017, 56, 834; c) E. Steffensmeier, M. T. Swann and K. M. Nicholas, Inorg. Chem., 2019, 58, 844.

12 B. M. Trost and J. S. Tracy, ACS Catal., 2019, 9, 1584.

13 a) J. L. Sessler, E. Tomat and V. M. Lynch, Chem. Commun., 2006, 4486; b) Y. E. Kandrashkin, M. S. Asano and A. van der Est, J. Phys. Chem. A, 2006, 110, 9607; c) S. K. Ghosh, R. Patra and S. P. Rath, Inorg. Chem., 2008, 47, 9848; d) K.-i. Yamashita, S. Tazawa and K.-i. Sugiura, Inorg. Chim. Acta, 2016, 439, 173; e) W. Chen, T. Suenobu and S. Fukuzumi, Chem. Asian J., 2011, 6, 1416; f) A. Doukkali, A. Saoiabi, M. Ferhat, Y. Mugnier, A. Vallat and R. Guilard, New J. Chem., 2006, 30, 997.

14 a) R. Kumar, N. Chaudhary, M. Sankar and M. R. Maurya, Dalton Trans., 2015, 44, 17720; b) T. A. Dar, B. Uprety, M. Sankar and M. R. Maurya, Green Chem., 2019, 21, 1757.

15 a) O. R. Simonova, S. V. Zaitseva and O. I. Koifman, Russ. J. Gen. Chem., 2016, 86, 1322; b) P. Schwendt, J. Tatiersky, L. Krivosudský and M. Šimuneková, Coord. Chem. Rev., 2016, 318, 135.

16 a) T. R. Cundari, L. Saunders, and L. L. Sisterhen, J. Phys. Chem. A, 1998, 102, 997; b) C. J. Schneider, G. Zampella, C. Greco, V. L. Pecoraro and L. De Gioia, Eur. J. Inorg. Chem., 2007, 515.

17 a) R. Salcedo, L. M. R. Martínez and J. M. Martínez-Magadán, J. Mol. Struct. Theochem., 2001, 542, 115; b) H.-B. Li, S. X. Tian and J. Yang, J. Phys. Chem. B, 2008, 112, 15807; c) S. R. Stoyanov, C.-X. Yin, M. R. Gray, J. M. Stryker, S. Gusarov and A. Kovalenko, Can. J. Chem., 2013, 91, 872.

18 Gaussian 09, Revision C.01, M. J. Frisch, G. W. Trucks, H. B. Schlegel, G. E. Scuseria, M. A. Robb, J. R. Cheeseman, G. Scalmani, V. Barone, B. Mennucci, G. A. Petersson, H. Nakatsuji, M. Caricato, X. Li, H. P. Hratchian, A. F. Izmaylov, J. Bloino, G. Zheng, J. L. Sonnenberg, M. Hada, M. Ehara, K. Toyota, R. Fukuda, J. Hasegawa, M. Ishida, T. Nakajima, Y. Honda, O. Kitao, H. Nakai, T. Vreven, J. A. Montgomery, Jr., J. E. Peralta, F. Ogliaro, M. Bearpark, J. J. Heyd, E. Brothers, K. N. Kudin, V. N. Staroverov, T. Keith, R. Kobayashi, J. Normand, K. Raghavachari, A. Rendell, J. C. Burant, S. S. lyengar, J. Tomasi, M. Cossi, N. Rega, J. M. Millam, M. Klene, J. E. Knox, J. B. Cross, V. Bakken, C. Adamo, J. Jaramillo, R. Gomperts, R. E. Stratmann, O. Yazyev, A. J. Austin, R. Cammi, C. Pomelli, J. W. Ochterski, R. L. Martin, K. Morokuma, V. G. Zakrzewski, G. A. Voth, P. Salvador, J. J. Dannenberg, S. Dapprich, A. D. Daniels, O. Farkas, J. B. Foresman, J. V. Ortiz, J. Cioslowski and D. J. Fox, Gaussian, Inc., Wallingford CT, 2010.

19 a) A. D. Becke, J. Chem. Phys., 1993, 98, 5648; b) C. Lee, W. Yang and R. G. Parr, Phys. Rev. B, 1988, 37, 785.

20 a) P. J. Hay and W. R. Wadt, J. Chem. Phys., 1985, 82, 270; b) W. J. Hehre, R. Ditchfield and J. A. Pople, J. Chem. Phys., 1972, 56, 2257.

21 a) D. Kumar, H. Hirao, L. Que Jr and S. Shaik, J. Am. Chem. Soc., 2005, 127, 8026; b) S. P. de Visser, J. Am. Chem. Soc., 2006, 128, 9813; c) L. Bernasconi and E.-J. Baerends, Eur. J. Inorg. Chem., 2008, 1672; d) S. F. Ye and F. Neese, Proc. Natl. 
Acad. Sci. USA, 2011, 108, 1228; e) M. Lundberg and T. Borowski, Coord. Chem. Rev., 2013, 257, 277; f) A. Timmins, M. Saint-André and S. P. de Visser, J. Am. Chem. Soc., 2017, 139, 9855; g) G. Mukherjee, A. Alili, P. Barman, D. Kumar, C. V. Sastri and S. P. de Visser, Chem. Eur. J., 2019, 25, 5086.

22 a) R. Latifi, M. A. Sainna, E. V. Rybak-Akimova and S. P. de Visser, Chem. Eur. J., 2013, 19, 4058; b) H. M. Neu, T. Yang, R. A. Baglia, T. H. Yosca, M. T. Green, M. G. Quesne, S. P. de Visser and D. P. Goldberg, J. Am. Chem. Soc., 2014, 136, 13845 ; c) T. Yang, M. G. Quesne, H. M. Neu, F. G. Cantú Reinhard, D. P. Goldberg and S. P. de Visser, J. Am. Chem. Soc., 2016, 138, 12375.

23 a) J.-U. Rohde, J.-H. In, M. H. Lim, W. W. Brennessel, M. R. Bukowski, A. Stubna, E. Münck, W. Nam and L. Que Jr, Science, 2003, 299, 1037; b) M. Martinho, F. Banse, J.-F. Bartoli, T. A. Mattioli, P. Battioni, O. Horner, S. Bourcier and J.-J. Girerd, Inorg. Chem., 2005, 44, 9592; c) A. S. Borovik, Acc. Chem. Res., 2005, 38, 54; d) E. Andris, R. Navrátil, J. Jašík, M. Puri, M. Costas, L. Que Jr and J. Roithová, J. Am. Chem. Soc., 2018, 140, 14391; e) S. Pattanayak, F. G. Cantú Reinhard, A. Rana, S. S. Gupta and S. P. de Visser, Chem. Eur. J., 2019, 25, 8092.

24 a) A. Ghosh, Acc. Chem. Res., 1998, 31, 189; b) M. T. Green, J. Am. Chem. Soc., 1999, 121, 7939; c) S. P. de Visser and L. S. Tan, J. Am. Chem. Soc., 2008, 130, 12961; d) M. Radoń, E. Broclawik and K. Pierloot, J. Chem. Theory Comput., 2011, 7, 898.

25 a) R. Latifi, M. Bagherzadeh and S. P. de Visser, Chem. Eur. J., 2009, 15, 6651; b) S. P. de Visser, J. Am. Chem. Soc., 2010, 132, 1087.

26 a) S. P. de Visser, F. Ogliaro, N. Harris and S. Shaik, J. Am. Chem. Soc., 2001, 123, 3037; b) D. Kumar, R. Latifi, S. Kumar, E. V. Rybak-Akimova, M. A. Sainna and S. P. de Visser, Inorg. Chem., 2013, 52, 7968.

27 a) S. Shaik, W. Lai, H. Chen and Y. Wang, Acc. Chem. Res. 2010, 43, 1154; b) D. Li, Y. Wang and K. Han, Coord. Chem. Rev., 2012, 256, 1137; c) D. Kumar, G. N. Sastry and S. P. de Visser, Chem. Eur. J., 2011, 17, 6196.

28 a) S. P. de Visser, F. Ogliaro, P. K. Sharma and S. Shaik, Angew. Chem. Int. Ed., 2002, 41, 1947; b) S. P. de Visser, F. Ogliaro, P. K. Sharma and S. Shaik, J. Am. Chem. Soc., 2002, 124, 11809; c) D. Kumar, L. Tahsini, S. P. de Visser, H. Y. Kang, S. J. Kim and W. Nam, J. Phys. Chem. A, 2009, 113, 11713.

29 a) S. P. de Visser, F. Ogliaro and S. Shaik, Angew. Chem. Int. Ed., 2001, 40, 2871; b) D. Kumar, B. Karamzadeh, G. N. Sastry and S. P. de Visser, J. Am. Chem. Soc., 2010, 132, 7656

30 a) D. Kumar, S. P. de Visser and S. Shaik, Chem. Eur. J., 2005, 11, 2825; b) M. A. Sainna, S. Kumar, D. Kumar, S. Fornarini, M. E. Crestoni and S. P. de Visser, Chem. Sci., 2015, 6, 1516.

31 a) A. S. Faponle, M. G. Quesne and S. P. de Visser, Chem. Eur. J., 2016, 22, 5478; b) M. Pickl, S. Kurakin, F. G. Cantú Reinhard, P. Schmid, A. Pöcheim, C. K. Winkler, W. Kroutil, S P. de Visser and K. Faber, ACS Catal. 2019, 9, 565; c) F. S. T. Khan, S. J. Shah, S. Bhowmik, F. G. Cantú Reinhard, M. A. Sainna, S. P. de Visser and S. P. Rath, Dalton Trans., 2019, 48, 6353.

32 a) F. Ogliaro, S. P. de Visser, S. Cohen, J. Kaneti and S. Shaik, ChemBioChem., 2001, 2, 848; b) X.-X. Li, V. Postils, W. Sun, A S. Faponle, M. Solà, Y. Wang, W. Nam and S. P. de Visser, Chem. Eur. J., 2017, 23, 6406.

33 S. P. de Visser, S. Shaik, P. K. Sharma, D. Kumar and W. Thiel, J. Am. Chem. Soc., 2003, 125, 15779.

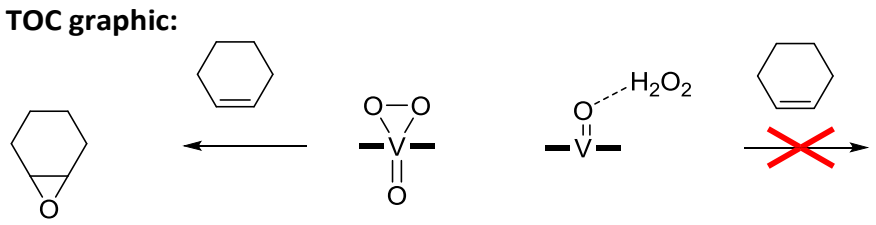

